\title{
"Allá está de balde y aquí me serviría". La circulación capilar de libros en guaraní en el Paraguay, el Río de la Plata y el espacio atlántico (siglo XVIII)
}

\author{
Fabián R. Vega ${ }^{1}$
}

Recibido: 4 de julio de 2019 / Aceptado: 15 de febrero de 2020

Resumen. Este artículo analiza la distribución de libros en guaraní a lo largo del Río de la Plata y el Paraguay. Las misiones ubicadas en los ríos Paraná y Uruguay eran el territorio central de producción y uso de estos materiales. Sin embargo, el objetivo de este artículo es explorar la menos conocida circulación externa de los libros y evaluar su radio de alcance. ¿Qué tan extendida estuvo esta circulación? ¿Qué libros se distribuyeron y cuáles no? ¿Cuáles fueron las razones? ¿Cuál fue el rol jugado por los misioneros y especialmente los jesuitas? Las fuentes principales para este análisis son los inventarios de las bibliotecas jesuíticas, la mayoría de ellos escritos en el contexto de la expulsión de los jesuitas de la monarquía hispánica (1767-1768). Aunque cuantitativamente escasa, esta circulación tuvo un alto grado de capilaridad. Los libros llegaron a todas las ciudades y misiones relevantes de la región e incluso a Europa. Tanto las redes misionales como las prácticas educativas cumplieron un rol relevante para explicar esta distribución capilar. Especialmente, los jesuitas de toda la provincia del Paraguay estaban obligados a aprender idiomas indígenas. En este sentido, la distribución de libros sugiere que la lengua guaraní era la lengua general colonial del territorio.

Palabras clave: Biblioteca; historia del libro; idioma guaraní; jesuitas; siglo XVIII.

\section{[en] "Allá está de balde y aquí me serviría". The Capillary Circulation of Guaraní Language Books in Paraguay, Rio de la Plata and the Atlantic Area (18 $8^{\text {th }}$ Century)}

\begin{abstract}
This article analyzes the distribution of books in Guarani along the La Plata River and in Paraguay. The missions located along the Parana and Uruguay rivers comprised the territorial center of the production and use of these materials. Yet, the objective of this article is to explore the less well known external circulation of these books and to assess the radius of their reach. How extensive was their circulation? Which books were distributed and which were not? For what reasons? What was the role of the missionaries, especially the Jesuits? The principal sources for this analysis are the inventories of the Jesuit libraries, the majority of which were compiled in the context of the expulsion of the Jesuits from the Spanish Monarchy (1767-1768). Although quantitatively scarce, their circulation achieved a high level of capillarity. The books reached all of the important cities and missions of the region and even as far as Europe. The missions' networks and their educational practices play an important role in the explanation of this capillary distribution, especially since the Jesuits of the entire Province of Paraguay were obligated to learn the indigenous languages. In this respect, the distribution of these books suggests that Guarani was the general colonial language of the territory.
\end{abstract}

Keywords: Library; History of book; Guaraní language; Jesuits; $18^{\text {th }}$ Century.

1 Consejo Nacional de Investigaciones Científicas y Técnicas (CONICET) [Argentina] - Instituto de Altos Estudios Sociales (Universidad Nacional de San Martín) [Argentina] - Universidad de Buenos Aires [Argentina].

E-mail: vegafabianr@gmail.com 
Sumario. 1. Presentación. 2. El guaraní, una lengua general colonial. 3. Inventarios de bienes y catálogos de libros: fuentes para el estudio de los libros en guaraní en las bibliotecas. 4. Los títulos en circulación. 5. Distribución de los libros en el Paraguay y el Río de la Plata. 6. Conexiones atlánticas. 7. Conclusión. 8. Referencias bibliográficas.

Cómo citar: Vega, F. R. (2020) “Allá está de balde y aquí me serviría”. La circulación capilar de libros en guaraní en el Paraguay, el Río de la Plata y el espacio atlántico (siglo XVIII), en Revista Complutense de Historia de América 46, 131-154.

\section{Presentación}

En este artículo exploramos la distribución y circulación geográfica de libros en o sobre la lengua guaraní colonial, dentro o a partir del Río de la Plata y el Paraguay. Desde hace quince años, los estudios académicos sobre esta lengua han cobrado un auge renovado y la han colocado en el centro de la agenda de investigación. El descubrimiento de novedosos documentos, la extensión de la enseñanza de esta lengua colonial, la constitución de redes internacionales de investigación y el énfasis de la historiografía en la producción y circulación de saberes misionales (etnográficos, cartográficos, históricos, botánicos, etc.) son factores que contribuyen a explicar este auge. Las bibliotecas constituyen una vía para conocer y explorar los saberes misionales de todo tipo. Entre los materiales más significativos de los repositorios bibliográficos coloniales se encuentran los libros en lenguas indígenas. Durante la primera mitad del siglo XX, bibliógrafos e historiadores describieron y rastrearon impresos en guaraní $i^{2}$. Pero el estudio concreto de la lengua, la política lingüística en torno de la misma y por lo menos algunos manuscritos llegarían solo de la mano de Bartomeu Melià (1932-2019) unas décadas más tarde ${ }^{3}$. Hoy en día, existen investigaciones renovadoras que se desarrollan a través de redes de Europa y América y que establecieron los rasgos centrales de una amplia cultura escrita misional, caracterizada por el conocimiento de la lectura y la escritura por parte de una porción relevante de la población indígena, la extensión de variadas prácticas de escritura, la producción constante de manuscritos, la existencia de grandes bibliotecas en las que la lengua guaraní ocupaba un rol central y la implicancia de la población indígena en el conjunto de la cultura letrada ${ }^{4}$.

Sin embargo, estos estudios no han recurrido en gran medida a materiales como los inventarios de bienes y los catálogos de libros. Para las misiones jesuíticas de guaraníes, de chiquitos y del Chaco, los inventarios fueron editados (parcialmente) por Francisco Javier Brabo ${ }^{5}$. Pero solo unos pocos inventarios de colegios jesuíticos se han publicado y la información permanece en gran medida inédita. Lo mismo puede decirse de las instituciones franciscanas ${ }^{6}$. En cambio, las bibliotecas particulares resultan más conocidas, aunque su importancia para los libros en guaraní es

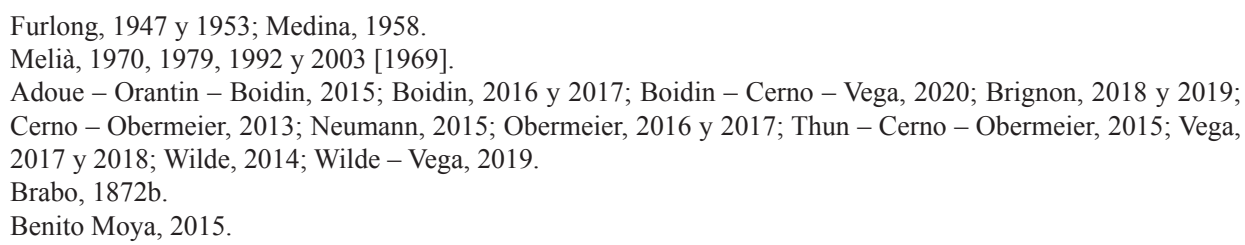


menor. Además, pocas investigaciones han tratado de pensar la interconexión espacial y geográfica al interior del Río de la Plata y el Paraguay coloniales a la hora de explorar la circulación de saberes misionales.

Las misiones de los ríos Paraná y Uruguay conformaron el territorio decisivo de producción y uso de los libros en guaraní. La circulación interna de estos materiales textuales se va conociendo cada vez con mayor precisión gracias a investigaciones recientes ${ }^{7}$. Pero es muy poco lo que sabemos sobre su circulación externa (hacia afuera de las misiones). Enfocarse en esta distribución permitiría revelar el alcance geográfico que tuvo el movimiento de libros en o sobre la lengua guaraní. Por eso aquí nos centramos en las instituciones del Río de la Plata y el Paraguay -fuera de los ríos Uruguay y Paraná- que albergaban en sus bibliotecas libros de este tipo. También tomamos en consideración la presencia de libros en algunas bibliotecas de la Península Ibérica, cuyos catálogos fueron digitalizados en el marco del proyecto Inventarios y Bibliotecas del Siglo de Oro (IBSO).

¿Qué tan extendida estuvo la circulación de libros en guaraní en el Río de la Plata y el Paraguay? ¿Qué tipo de materiales se distribuyeron y cuáles no? En el caso de constatar esa circulación, ¿qué factores permitirían explicarla? ¿Qué rol cumplieron los misioneros y especialmente los jesuitas en esta circulación? El objetivo de este artículo es responder estas preguntas. La hipótesis central es que existió distribución de libros en guaraní a lo largo de todo el Río de la Plata y el Paraguay. La cantidad distribuida fue escasa y no alcanzó a representar un porcentaje significativo en ninguna biblioteca. Pero la circulación tuvo un grado alto de capilaridad y alcanzó todas las ciudades y misiones importantes -e, incluso, algunas bibliotecas españolas. Esta idea resalta la importancia de la distribución sobre la cantidad, especialmente cuando tratamos de libros cuya tirada fue escasa. Los misioneros, sobre todo los jesuitas, participaban de un proceso constante de aprendizaje de lenguas indígenas, entre ellas el guaraní. Argumentamos que en función de las necesidades de evangelización y de sus redes de circulación, los misioneros extendieron el alcance geográfico de una lengua cristiana elaborada en principio en un territorio reducido. La distribución bibliográfica amplió los marcos espaciales de la lengua guaraní. Al menos hasta la década de 1760, los jesuitas monopolizaron esta circulación como consecuencia de su actividad de misioneros en el Paraguay y de su control de las instituciones educativas. En este sentido, sugerimos que la lengua guaraní podría considerarse no sólo un saber misional, sino el idioma indígena por excelencia de la provincia jesuítica del Paraguay.

Los documentos utilizados en esta investigación se produjeron en el contexto de la expulsión de la Compañía de Jesús de la monarquía hispánica (1767-1768). Los jesuitas habían establecido las primeras misiones en la región a comienzos del siglo XVII, pero una serie de conflictos determinaron la ruptura con las autoridades monárquicas. Como parte de la expulsión, las autoridades inventariaron los bienes de los jesuitas para rematarlos o distribuirlos. En este marco se elaboraron muchos de los inventarios de bibliotecas. Decidimos no avanzar más allá de 1770-1780 porque, con posterioridad al proceso de inventariado de bienes, varias bibliotecas se dispersaron y resulta difícil rastrear e identificar libros individuales. Aunque no restringimos la investigación a los jesuitas, estos gozan de protagonismo, puesto que fueron los actores nucleares en la escritura de los primeros libros en guaraní.

Gutiérrez, 2004; Obermeier, 2016; Vega, 2018. 


\section{El guaraní, una lengua general colonial}

El uso de lenguas indígenas fue una característica de la evangelización católica en América colonial. Las principales instancias organizativas de la Iglesia en el Virreinato del Perú, los Concilios de Lima, sancionaron la evangelización de los indios en sus propias lenguas ${ }^{8}$. Pero esto no significó que todas las lenguas tuviesen la misma jerarquía para los evangelizadores. Aquellas que se utilizaron en el proceso de conversión fueron las "lenguas generales coloniales", según la categoría histórico-lingüística de Estenssoro e Itier9. La categoría se diferencia de otros conceptos de la sociolingüística, como lenguas vehicular, franca o koinè. La lengua general colonial no era ni un idioma simplificado ni un idioma compuesto no hablado de forma materna por ningún grupo. Tampoco coincidió exactamente con las lenguas generales prehispánicas. Fue más bien "la lengua de un grupo [indígena] mayoritario o políticamente preponderante", con hablantes distribuidos por amplios espacios y fundamentalmente pluri-étnica. Se opuso a las lenguas indígenas maternas, el primer idioma hablado por cada individuo. A partir de su incorporación como instrumento de la política imperial colonial, la lengua general extendió su radio de comprensión $\mathrm{y}$ asumió la función de lengua de cultura ${ }^{10}$. Entre estas, cabe incluir las lenguas que articularon un virreinato o una colonia enteras -quechua, náhuatl, tupí- y las que, como el guaraní, conectaron macro-regiones con reducida presencia estatal y preponderancia eclesiástica ${ }^{11}$ pero permanecieron atadas a su carácter de lengua natural, reflejado en el etnónimo usado para nombrarlas ${ }^{12}$. El tupí y el guaraní son lenguas muy cercanas, de modo que podría decirse, con Capucine Boidin, que en la época colonial existía una lengua general desde la costa atlántica de Brasil hasta el piedemonte andino ${ }^{13}$. El proceso de generalización de una lengua indígena fue resultado de la colonización y el impulso evangelizador.

En el Paraguay, el uso del guaraní para la evangelización fue impulsado por los franciscanos desde 1575. Luis de Bolaños (1539-1629) fue el más importante de ellos; escribió las primeras gramática y vocabulario de la lengua y tradujo el catecismo aprobado por el Tercer Concilio ${ }^{14}$. Al mismo tiempo que Bolaños, los jesuitas de Brasil empezaron a trabajar sobre el tupí ${ }^{15}$. Estas dos experiencias, y la circulación de textos que impulsaron, resultaron precedentes importantes del accionar de los jesuitas del Paraguay, quienes se comunicaron en guaraní con la población indígena del Paraná, Uruguay, Itatín, Guairá y Tape desde el establecimiento de la primera misión (1609) hasta la expulsión (1767-1768). En Brasil existió una amplia producción lingüística sobre el tupí, pero en el siglo XVI sólo alcanzó la imprenta el Arte de grammatica da lingoa mais usada na costa do Brasil (1595) de José de Anchieta (1533-1597) ${ }^{16}$. Entre tanto, de los trabajos de los franciscanos (que tuvieron también una amplia circulación manuscrita) solo llegaron a imprimirse algunos pequeños

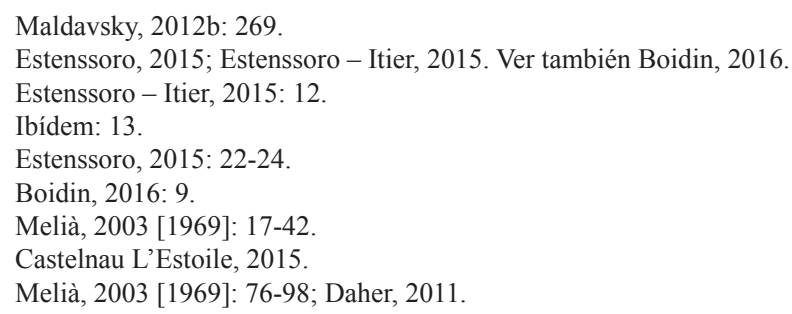


textos de Bolaños en Rituale, seu manuale peruanum (1607), una compilación en diversas lenguas indígenas realizada por Luis Jerónimo de Oré (†1629) e impresa en Nápoles. Una carta de 1610 del jesuita Francisco San Martín (nacido en 1581), escrita desde Asunción, menciona el uso del libro de Anchieta y de los apuntes de Bolaños para el aprendizaje del guaraní. En general, los textos de Bolaños, oficializados en el Sínodo de Asunción (1603), resultaron clave en la obra de los jesuitas ${ }^{17}$.

La consolidación definitiva del guaraní como lengua general fue consecuencia de la amplia producción textual jesuítica en los siglos XVII y XVIII ${ }^{18}$. En la primera de estas centurias, Antonio Ruiz de Montoya (1585-1652) publicó en Madrid el Tesoro de la lengua guarani (1639), el Arte y bocabulario de la lengua guarani (1640) y el Catecismo de la lengua guarani (1640). En la siguiente centuria, el misionero Pablo Restivo (1658-1740), sobre la base del trabajo previo de Montoya, escribió un Vocabulario de la lengua guarani (1722) y un Arte de la lengua guarani (1724), impresos en las reducciones del Paraguay, a partir de una prensa establecida por jesuitas e indígenas ${ }^{19}$. En esta imprenta los religiosos produjeron además tres libros monolingües en guaraní: la traducción por José Serrano (1634-1713) de De la diferencia entre lo temporal y lo eterno (1705) de Juan Eusebio Nieremberg ${ }^{20}$ y los libros Explicación de el catechismo en lengua guaraní (1724) y Sermones y exemplos en lengua guaraní (1727) del cacique Nicolás Yapuguay ${ }^{21}$. También imprimieron un texto híbrido que contiene secciones en guaraní y en latín: el Manuale ad usum Patrum Soceitatis Iesu (1721), escrito por Restivo ${ }^{22}$. El último impreso jesuítico en guaraní se editó en Madrid en dos volúmenes en 1759 y 1760, con el título de Ara Poru agǔyey haba (Buen uso del tiempo) y atribución autoral a José Insaurralde (1663-1730) ${ }^{23}$.

Además de los impresos, en este período se escribieron varios manuscritos en o sobre la lengua guaraní. Algunos fueron redactados por Restivo, pero no debería descartarse la autoría y colaboración indígena en varios otros casos. Estos escritos fueron ignorados durante décadas por la investigación especializada, pero en los últimos años se han convertido en un objeto privilegiado de indagación. Existe una deuda pendiente relativa a la catalogación sistemática de estos materiales. La mayor parte de los manuscritos en guaraní estaban concentrados en las misiones y su distribución fuera de este espacio - objeto del presente trabajo-resultó más bien reducida. Por lo demás, cabe destacar que, aparte del libro ya mencionado de Anchieta, otros textos sobre el tupí -escritos en Brasil y publicados en Portugal en los siglos XVII y XVIII- no tuvieron influencia sobre la producción del Paraguay y el Río de la Plata, sea impresa o manuscrita. Ninguno estaba presente en las bibliotecas locales.

Antes de la evangelización, el guaraní era una lengua heterogénea con infinidad de variedades dialectales. Esas variedades siguieron existiendo, pero la creación de gramáticas y vocabularios inventó, canonizó y congeló una variante determinada del idioma ${ }^{24}$. Además de esto, el esfuerzo misionero (franciscano y jesuítico) implicó transformaciones profundas, puesto que los religiosos debieron cristianizar una

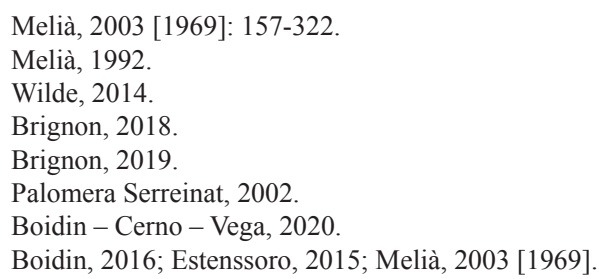


lengua que carecía del vocabulario adecuado para transmitir el mensaje católico. La cristianización fue un componente lateral de un conflicto político y religioso más amplio que enfrentó a mediados del siglo XVII al obispo de Asunción -el franciscano Bernardino de Cárdenas (1579-1670) - y a los jesuitas de las misiones ${ }^{25}$. El obispo criticó el uso de ciertas palabras en guaraní para transmitir la doctrina cristiana, entre ellas Tupã (Dios). Aunque los argumentos de los jesuitas fueron variados, uno de ellos apuntaba a que el catecismo utilizado en las misiones era el redactado por el franciscano Bolaños y a que la traducción de los conceptos no era una invención jesuítica. El resultado lingüístico-religioso de la polémica fue favorable a los jesuitas y se siguieron utilizando los conceptos en disputa.

Desde comienzos del siglo XVII los misioneros aprendieron otros idiomas además del guaraní. En gran parte de la región, los indígenas hablaban variantes del quechua, lengua general del Virreinato del Perú. Las cartas anuas tempranas muestran que los misioneros también aprendieron algunas otras lenguas de carácter materno o particular ${ }^{26}$. Con el paso del tiempo, incluso desarrollaron una cierta producción textual en otras lenguas, que alcanzaría la imprenta con la publicación del Arte y vocabulario de la lengua lule y tonocoté (1732) del jesuita Antonio Machoni (16721753). Estas lenguas no alcanzaron un grado relevante de generalidad y la producción textual en guaraní concentró la mayoría de los esfuerzos de los misioneros de la región.

\section{Inventarios de bienes y catálogos de libros: fuentes para el estudio de los libros en guaraní en las bibliotecas}

La disciplina de la historia del libro utilizó inventarios de bibliotecas como fuentes desde mediados del siglo XX. Inicialmente, los investigadores consideraron que estos documentos evidenciaban la historia intelectual o las "mentalidades" de un período dado. Más tarde, un autor como Roger Chartier formuló reparos a esta perspectiva, al mismo tiempo que reconoció que una aproximación estadística preliminar era un paso necesario antes de avanzar hacia una historia cultural más amplia ${ }^{27}$. Recientemente, algunos historiadores de las bibliotecas postularon que las "librerías" temprano-modernas no eran solo un reflejo de la sociedad, sino más bien agentes activos que funcionaron como áreas de trabajo, instrumentos de prestigio y espacios de sociabilidad. Las bibliotecas eran el producto a la vez que el estímulo de redes geográficas, culturales y lingüísticas y constituyen la condición de posibilidad de los conocimientos producidos en el marco de la república de las letras ${ }^{28}$. Desde esta perspectiva, la presente investigación pretende hacer un aporte al conocimiento de la historia cultural del Río de la Plata y el Paraguay. El rastreo de la circulación y distribución de libros requiere documentos que informen sobre los contenidos de las bibliotecas. Existen tres conjuntos de materiales al respecto: los inventarios de bienes post mortem de personas particulares ${ }^{29}$, los catálogos de bibliotecas de ór-

\footnotetext{
Avellaneda, 2014; Melià, 2003 [1969]: 209-260.

Baigorri Jalón - Araguás, 2007.

Chartier, 1994.

Bertrand - Cayuela - Del Vento - Mouren, 2016.

Comadrán Ruiz, 1961; Furlong, 1944; Revello, 1965.
} 
denes religiosas realizados por los propios miembros ${ }^{30} \mathrm{y}$ los inventarios de bienes de instituciones jesuíticas que se confeccionaron en el contexto de expulsión de la Compañía y confiscación de sus bienes (desde 1767-1768) ${ }^{31}$.

La casi totalidad de los libros en guaraní pertenecían a bibliotecas de colegios, residencias y misiones jesuíticas. El único catálogo jesuítico anterior a la expulsión es de 1757; corresponde al Colegio Máximo de Córdoba y está editado ${ }^{32}$. Para las otras instituciones, usamos los inventarios posteriores a 1767. De estos, se encuentran editados los de Asunción ${ }^{33}$, San Miguel de Tucumán ${ }^{34}$ y Mendoza ${ }^{35}$; existe también un extenso comentario sobre el contenido de la biblioteca del colegio de Buenos Aires $^{36}$. Los colegios más importantes estaban en las ciudades de Córdoba (Colegio Máximo), Buenos Aires (Colegio Grande de San Ignacio y Colegio Menor de Belén) y Asunción. Hacia 1767, en todas estas ciudades los jesuitas mantenían enseñanza de primeras y segundas letras; en Buenos Aires había además cátedras universitarias, pero la única institución de la que podían obtenerse grados universitarios era el Colegio Máximo. Fuera de algunas investigaciones clásicas como las de Guillermo Furlong, la mayoría de los colegios jesuíticos son todavía poco conocidos para la investigación, sea desde la historia del libro o desde la historia intelectual, hecha la excepción de Córdoba ${ }^{37}$ y Asunción ${ }^{38}$.

En el contexto de la expulsión de los jesuitas, el objetivo de la realización de inventarios de bienes era esencialmente comercial, pero las órdenes reales postulaban que las bibliotecas debían ser entregadas a instituciones de enseñanza. En el caso de los libros en lenguas indígenas, estos fueron requeridos para controlar sus contenidos, ser enviados a las reducciones indígenas o ser depositados en los seminarios de formación de sacerdotes ${ }^{39}$. El Consejo de Indias indicaba en abril de 1768 que "en algunos colegios" debía promoverse "la enseñanza de la lengua de los indios", para lo cual se hacía necesario recoger "gramáticas, diccionarios, y otras obras que hubieren dejado los Regulares en sus casas, colegios ó residencias" ${ }^{40}$. Existe una orden de Juan José de Vértiz, gobernador de Buenos Aires entre 1770 y 1776 (y virrey entre 1778 y 1784), en la que solicita a Córdoba el envío de un inventario de libros jesuíticos que pusiera especial cuidado en la anotación de diccionarios y gramáticas en lenguas indígenas ${ }^{41}$. Las distintas órdenes relativas a los inventarios de bienes puntualizaban reglas para la anotación de los libros, pero en general no fueron cumplidas.

30 Benito Moya, 2011, 2012, 2015 y 2017 Fraschini, 2005a y 2005b; Llamosas, 2012.

31 Draghi Lucero, 1949; Gutiérrez, 2004; Lovay, 2017; Robledo de Selassie, 1976; Vega, 2017 y 2018. Para una síntesis general, véase Parada, 2003. Aunque no hicimos una indagación sistemática, en los inventarios de bibliotecas particulares solo encontramos libros en guaraní a partir de 1801 (fuera del período considerado en este trabajo). Torre Revello identificó libros en guaraní en la biblioteca del presbítero José González de Isla, fallecido en 1801 (Revello, 1965: 58-59). A su vez, sólo se hallamos dos libros en guaraní en una biblioteca no jesuítica, la del convento franciscano en Córdoba, según un inventario del siglo XVIII (véase más adelante).

32 Fraschini, 2005a y 2005b.

33 Gorzalczany - Olmos Gaona, 2006.

34 Robledo de Selassie, 1976.

35 Draghi Lucero, 1949.

36 Revello 1965: 66-73.

37 La principal excepción es Córdoba: Benito Moya, 2011 y 2012; Llamosas, 2008 y 2011.

38 Telesca, 2009.

39 Benito Moya, 2012.

40 Brabo, 1872a: 99.

41 Benito Moya, 2012: 22. 
Los inventarios hoy existentes carecen de datos esenciales sobre los libros (como la fecha y ciudad de impresión), lo que dificulta sobremanera su identificación.

La mayor parte de los inventarios -sea en sus versiones originales o en copias certificadas- se conservan en el Archivo General de la Nación de Buenos Aires ${ }^{42}$, el Archivo Nacional de Chile de Santiago ${ }^{43}$ y, en menor medida, el Archivo Nacional de Bolivia de Sucre ${ }^{44}$. Probablemente haya inventarios distribuidos en otras instituciones. De los listados de bienes específicos de colegios, el único que no hemos podido hallar es el de Tarija. Esta institución formaba parte de la provincia del Paraguay y estuvo inicialmente muy vinculada a las misiones de chiriguanos y chiquitos.

Al menos en el caso de los colegios jesuíticos, resulta especialmente laxa la forma como se han inventariado los libros en guaraní, probablemente por el desconocimiento de quienes redactaron los catálogos. En este sentido, es posible que los libros de lingüística guaraní que escribió en el siglo XVIII Pablo Restivo se hayan atribuido, en su mayoría, a Antonio Ruiz de Montoya ${ }^{45}$. Esto podría explicar por qué existe una mayor cantidad de textos de Ruiz de Montoya que de Restivo en estas instituciones (véase más abajo), preponderancia que no se percibe con tanta claridad en las reducciones de guaraníes ${ }^{46}$. Del mismo modo, y a pesar de los títulos precisos que figuran en las portadas de los libros, es común encontrar combinaciones de palabras que aluden ambiguamente a varios libros o que no aportan la suficiente información para distinguir entre un libro u otro. En el primero de estos casos, es posible que se trate de una referencia a la encuadernación conjunta de dos impresos distintos. Pero, en general, este tipo de problemas genera dificultades a la hora de la identificación del libro en sentido estricto. No existe una metodología que se pueda aplicar en todos los casos para resolver esto, y creemos que por lo general debe mantenerse la cautela ante interpretaciones riesgosas.

\section{Los títulos en circulación}

Los resultados de la identificación y contabilización de los títulos se plasman en la Tabla 1, el Gráfico 1 y el Mapa 1. Independientemente de los posibles errores en la atribución de los libros, los tres títulos más distribuidos eran el Tesoro de la lengua guaraní (1639), el Arte y bocabulario de la lengua guaraní (1640) (ambos

42 Sin pretensión de exhaustividad, los inventarios relativos a colegios, residencias y reducciones indígenas diferentes a las del Paraná y el Uruguay se encuentran en: Archivo General de la Nación [Argentina] (en adelante AGN), Sala IX, 07-03-07 (Buenos Aires); 22-01-02, 22-01-03, 22-01-04 y 22-01-06 (Salta); 22-03-01 (Mendoza); 22-03-05, 22-03-06 y 22-04-01 (Santa Fe); 22-04-02 (Catamarca); 22-05-01 y 22-05-03 (Santiago del Estero); 22-06-01 (Jujuy); 22-06-05 y 22-06-07 (Corrientes); 22-07-02 (La Rioja); 22-07-03 (San Luis); 22-09-01 (Asunción); 22-09-03 (Montevideo). Los inventarios de algunas reducciones de indios no guaraníes (especialmente del Gran Chaco) están esparcidos en estos legajos. Una serie de legajos correspondientes a Córdoba fueron trasladados en abril de 2001 desde el Archivo General de la Nación a la Universidad Nacional de Córdoba (Fraschini, 2005a: 4-14). Los datos para este territorio puntual fueron extraídos de las fuentes editadas (Fraschini, 2005a y 2005b; Lovay, 2017).

43 Archivo Nacional de Chile [Chile], Jesuitas, Volúmenes 146 (Montevideo, La Rioja), 147 (Tucumán, La Rioja, Asunción), 148 (San Luis, Mendoza), 149 (Salta), 150 (Chaco), 151 (Santiago del Estero) y 152 (Santiago del Estero, Salta, Jujuy).

44 Archivo y Biblioteca Nacionales de Bolivia, Audiencia de La Plata, Mojos y Chiquitos, Documentos 60, 61 y 71.

45 Ciertamente las portadas de estos libros aludían a Antonio Ruiz de Montoya. A pesar de esto, en los inventarios de las misiones de guaraníes, que fueron realizados por los mismos jesuitas, a menudo se atribuyen a Restivo.

46 Vega, 2018. 
de Ruiz de Montoya) y el Ara Poru agulyey haba (1759-1760) de Insaurralde. Los tres fueron impresos en Madrid. Con la excepción del Catecismo (1640) de Ruiz de Montoya, esto muestra que los impresos madrileños estaban mucho mejor distribuidos que los impresos misionales en el espacio del Río de la Plata y el Paraguay. Los impresos madrileños tuvieron una mayor tirada que los de las reducciones, probablemente por razones técnicas ${ }^{47}$. Por ejemplo, los religiosos imprimieron mil quinientos ejemplares de los dos volúmenes de Ara Poru aguŭyey haba ${ }^{48}$. En cualquier caso, la circulación regional de libros en o sobre guaraní fue mayor en el siglo XVII que en el XVIII.

Tabla. 1. Libros en lengua guaraní distribuidos fuera de las reducciones del Paraná y el Uruguay ${ }^{49}$.

\begin{tabular}{|c|c|c|c|c|c|c|c|c|c|c|c|c|c|c|c|c|c|c|}
\hline Espacio y libro & 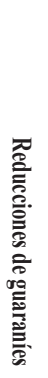 & 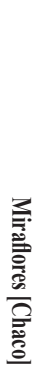 & 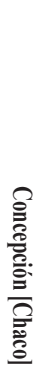 & 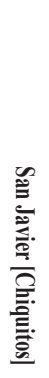 & 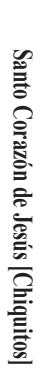 & 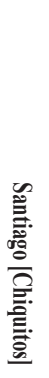 & $\frac{\varrho}{\circ}$ & 㝘 & 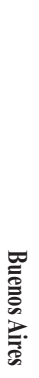 & 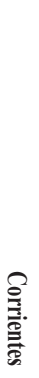 & 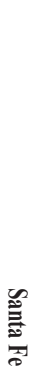 & $\begin{array}{l}\text { 몽. } \\
\text { 즘. }\end{array}$ & $\underset{\mathscr{W}}{\mathscr{\#}}$ & 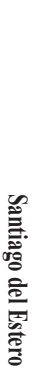 & $\begin{array}{l}\frac{2}{0} \\
\frac{0}{0} \\
\frac{0}{2} \\
\frac{1}{8}\end{array}$ & 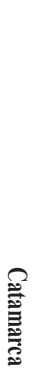 & 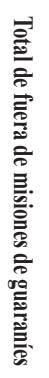 & $\overrightarrow{\overrightarrow{\underline{D}}}$ \\
\hline Montoya. Tesoro & 46 & & & & 1 & & 1 & 13 & & 5 & & 1 & 1 & 1 & & & 23 & 69 \\
\hline Montoya. Arte y bocabulario & 46 & & & & & & 2 & 13 & 12 & 4 & & & 3 & & & & 34 & 79 \\
\hline Montoya. Tesoro + Arte & 13 & & & & & & & & & & & & & & & & 0 & 13 \\
\hline Montoya. Catecismo & 78 & & & & & 1 & 1 & 1 & 1 & 3 & & & 1 & & & & 8 & 86 \\
\hline Serrano-Nieremberg & 2 & & & & & & 1 & & 1 & & & & & & & & 2 & 4 \\
\hline Restivo. Manuale & 16 & & & & & & & & & & & & & & & & 0 & 16 \\
\hline Restivo. Vocabulario & 28 & & & & & & & 3 & & 4 & & & & & & & 7 & 35 \\
\hline Restivo. Arte & 34 & & & & & & & & 1 & 4 & & & & & & & 5 & 39 \\
\hline Restivo. Vocabulario + Arte & 21 & & & & & & & & & & & & & & & & 0 & 21 \\
\hline Yapuguay. Catecismo & 23 & & & & & 1 & & 4 & 1 & 1 & 1 & & & & & & 8 & 31 \\
\hline Yapuguay. Sermones & 25 & & & & & & & & & 2 & & & & & & & 2 & 27 \\
\hline Insaurralde. Ara Poru & 807 & & & & & & 2 & 4 & 8 & 3 & & & 2 & & 3 & 2 & 24 & 831 \\
\hline
\end{tabular}

47 Los datos globales expuestos en Vega, 2018 demuestran que esto fue efectivamente así.

48 Boidin - Cerno - Vega, 2020.

49 Elaboración propia con base en las fuentes mencionadas en la nota 42 y en Vega, 2018. 


\begin{tabular}{|c|c|c|c|c|c|c|c|c|c|c|c|c|c|c|c|c|c|c|}
\hline Otros & 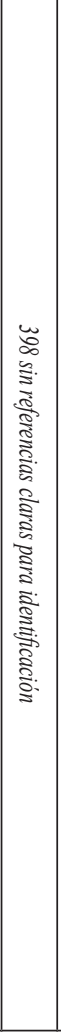 & 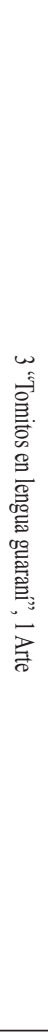 & 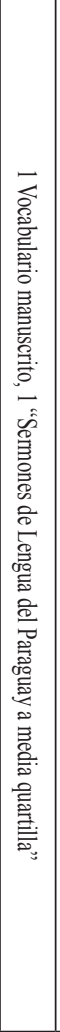 & 案 & & 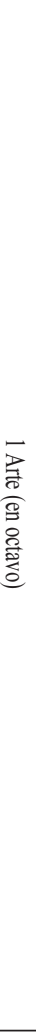 & 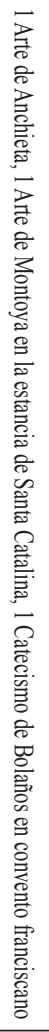 & 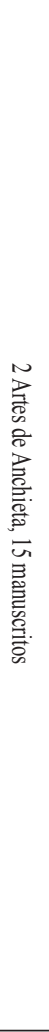 & 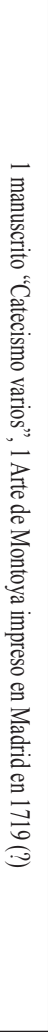 & 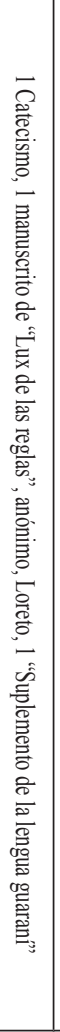 & 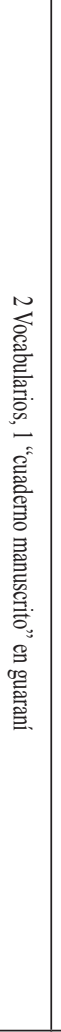 & 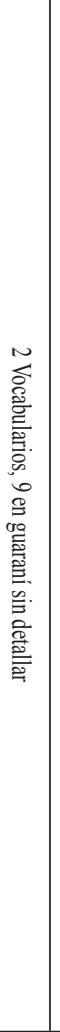 & 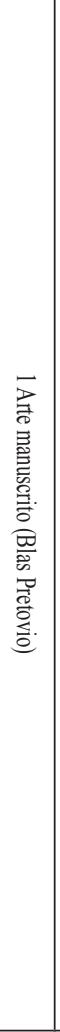 & 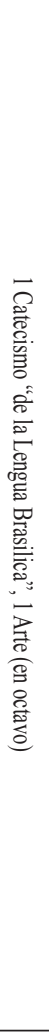 & & & 50 & 448 \\
\hline Total & 1537 & 4 & 2 & 1 & 1 & 3 & 10 & 55 & 26 & 29 & 4 & 12 & 8 & 3 & 3 & 2 & 162 & 1700 \\
\hline
\end{tabular}

Gráfico 1. Libros en lengua guaraní según su distribución fuera de las misiones del Paraná y el Uruguay ${ }^{50}$.

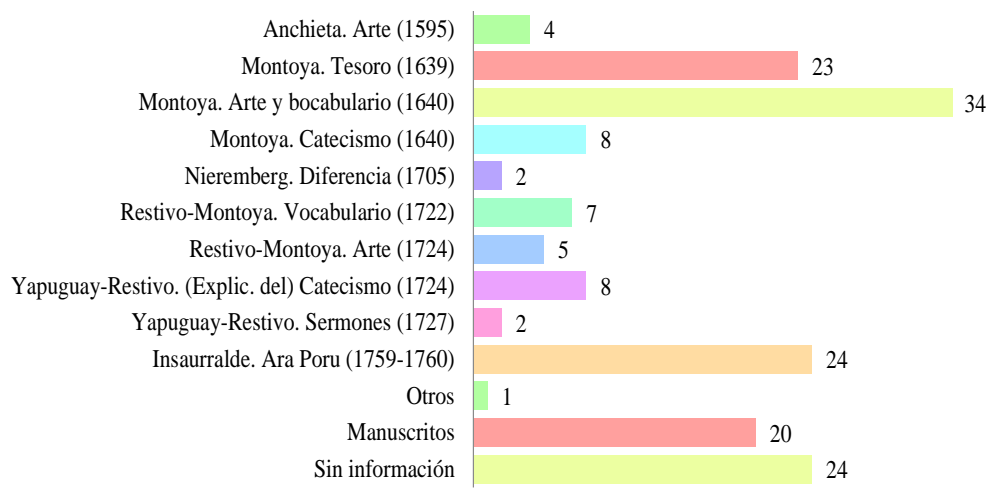

50 Elaboración propia con base en las fuentes mencionadas en la nota 42. Cabe destacar que los inventarios incluyen referencias a unos pocos libros desconocidos. En el colegio de Buenos Aires se menciona un libro de Ruiz de Montoya titulado "Arte de la lengua guaraní” e impreso en Madrid en 1719. No se han conservado libros de Montoya con estas características, y las ediciones de textos lingüísticos de este autor conocidas corresponden a impresos madrileños de los años 1639 y 1640. Lo más seguro es concluir que aquí estamos en presencia de errores de catalogación -y no de libros desconocidos hasta ahora-. Este libro de Montoya es el que aparece categorizado como "Otros” en el gráfico. 
Del Gráfico 1 y la Tabla 1 resulta claro que la mayoría de los libros en guaraní registrados en los inventarios eran impresos. Pero la proporción de manuscritos es relevante. Fernando Bouza ha demostrado que, en la modernidad temprana, la menor cantidad de copias de textos disponibles a través del manuscrito no implica que no pudieran difundirse ${ }^{51}$. La circulación de textos no requiere la impresión de los mismos. Es probable que los manuscritos hayan sido redactados en espacios guaraníparlantes, como Asunción, Corrientes y las misiones. Algunos se conservan al día de hoy. El manuscrito Catecismos varios, depositado en la British Library y estudiado por Melià ${ }^{52}$, se guardaba en el colegio jesuítico de Buenos Aires ${ }^{53}$. Un manuscrito atribuido a Blas Pretovio -según una interpretación discutida, acrónimo de Pablo Restivo-, se conservaba en el colegio de Salta, del cual Restivo mismo fue rector. Se han preservado muchos manuscritos atribuidos a Blas Pretovio ${ }^{54}$. En el colegio de Corrientes existía un manuscrito titulado Lux de las reglas. Documentos de la Lengua Guaraní que no hemos podido identificar. A pesar de una circulación evidente, la mayoría de los manuscritos se encontraba en una ciudad guaraní-parlante, Asunción. El inventario contiene las palabras iniciales y finales de estos manuscritos junto con su traducción al castellano ${ }^{55}$. Si pudiese probarse que estos textos se escribieron en Asunción, el inventario se convertiría en una fuente importante y virtualmente única para el estudio de la variante criolla colonial del guaraní. Se trata tanto de manuscritos doctrinarios como lingüísticos: textos sobre el nacimiento de Cristo, pláticas de la Virgen, sermonarios y otros libros de contenido similar. En Asunción también había dos textos atribuidos a Blas Pretovio y uno de Alonso d'Aragona ${ }^{56}$.

\section{Distribución de los libros en el Paraguay y el Río de la Plata}

El guaraní era la lengua hablada en las reducciones jesuíticas y franciscanas de guaraníes, en las ciudades criollas de Asunción y Corrientes y entre algunos sectores de población indígena no cristianizada de la región. La mayoría de los libros en guaraní (un 90\%) se conservaba en las misiones jesuíticas de guaraníes, espacio privilegiado de producción textual en esta lengua. En el Gráfico 2 se representan las proporciones de libros en guaraní en función del tipo de institución (reducciones de guaraníes, colegios, residencias y

\footnotetext{
51 Bouza, 2001.

52 Melià, 2003 [1969]: 273-322.

53 British Library [Reino Unido], Add. 21262.

54 En efecto, existe un Arte de la lengua guaraní conservado en la Biblioteca Universitaria de Granada (España; véase el ejemplar digitalizado en: http://adrastea.ugr.es/tmp/_webpac2_1112971.12851; un Compendio de los vocabulos mas usados de la lengua española y guaraní, sacados del vocabulario del Padre Blas Pretorio de la Compañia de Jesús en el Museo Mitre (Buenos Aires, Argentina); y un Vocabulario de lengua guaraní en la Biblioteca Jagiellonian (Cracovia, Polonia; véase el ejemplar digitalizado en: https://jbc.bj.uj.edu.pl/dlibra/ publication/343963/edition/328511/content?ref=desc. La información relativa a estos manuscritos ha sido compilada por Obermeier (Obermeier 2017, 10-11).

55 Telesca, 2009: 144-151 transcribe los fragmentos en guaraní.

56 No hemos encontrado el manuscrito Lo que pasó en la guerra, recientemente traducido y editado: Thun - Cerno - Obermeier 2015. Hay indicios de que este documento se encontraba en manos de los jesuitas en Buenos Aires en el siglo XIX. En un apunte de 1837, el intelectual y coleccionista Pedro de Angelis anotó que los "Padres Jesuitas de Buenos Aires" -reinstalados en la región gracias al breve apoyo de Juan Manuel de Rosas- "[p]oseen también una obrita manuscrita de la historia de la guerra de 1704 en las Misiones". Véase Pedro de Angelis, “Apuntes para la bibliografia de los libros en lengua guarani”. Buenos Aires, 1837. AGN, Sala VII, Colección Pedro de Angelis, Legajo 96.
} 
reducciones de indígenas no guaraní-parlantes), considerando datos de la Compañía de Jesús y combinando la información de este trabajo con la que publicamos en un trabajo previo $^{57}$. La presencia de libros en guaraní en los colegios, las residencias y las reducciones de Chaco y Chiquitos era minoritaria. Ninguna otra institución podía compararse con las misiones de los ríos Paraná y Uruguay y, en especial, con el pueblo de Candelaria, que acumulaba 1053 libros en o sobre esta lengua (un 62\% de los 1700 totales).

No obstante, la situación del Río de la Plata y el Paraguay es más compleja. La concentración de libros en Candelaria y las misiones no debería invisibilizar la existencia de una distribución capilar de libros en guaraní en todo el territorio. La tirada de estos libros fue escasa y por tanto resultaría difícil que muchos de ellos pudieran alcanzar espacios distantes. Independientemente de las cantidades, esto da cuenta de la existencia de redes para la circulación de estos materiales. La distribución muestra que existían algunos focos centrales de concentración de textos en guaraní: además de Candelaria y algunas otras misiones, Asunción, Corrientes y Buenos Aires están en los primeros lugares (Mapa 1). Asunción poseía 55 libros, Corrientes, 29 y Buenos Aires, 26. Pero, aunque estas ciudades del litoral -las más cercanas a las reducciones- concentraban muchos de los libros, los textos no se conservaban exclusivamente allí. Por ejemplo, en La Rioja había 12 libros, en Córdoba 10 y en Salta 9. Aunque en menores cantidades, algunas reducciones de indios no guaraníes poseían libros en este idioma. Miraflores, pueblo de lules, poseía 4, mientras que Santiago (de chiquitos) conservaba 3.

Gráfico 2. Distribución de volúmenes de libros en guaraní en instituciones jesuíticas del Paraguay según espacio y tipo de institución ${ }^{58}$.

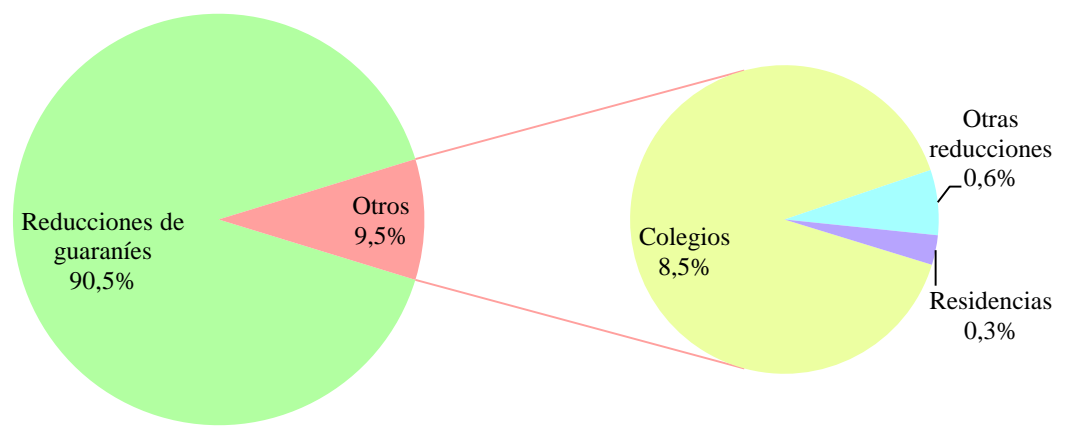

Esta distribución capilar da cuenta de la existencia de redes subterráneas que estimularon la circulación de materiales en guaraní, muy poco investigadas. No existe un estudio sistemático sobre la circulación de misioneros entre espacios o los canales de distribución de la cultura material en el Río de la Plata. Los agentes administrativos y económicos de las órdenes religiosas probablemente hayan jugado un rol central, como se ha demostrado para otras geografías ${ }^{59}$. Con la información existente se pueden elaborar algunas hipótesis indiciarias sobre la circulación regional de libros en guaraní. Para empezar, los jesuitas de la provincia del Paraguay estaban obligados a dominar una lengua indígena para ordenarse como sacerdotes, incluso aunque residiesen en un colegio urbano y no en una

\footnotetext{
Vega, 2018.

Elaboración propia con base en las fuentes mencionadas en la nota 42 y en Vega, 2018.

Alcalá Donegani, 2007; Galán García, 1995.
} 
misión. Esta política precede a la fundación de la provincia del Paraguay: ya en la década de 1580 el prepósito general Claudio Aquaviva había ordenado que en provincias de América fuese obligatorio el aprendizaje de lenguas indígenas ${ }^{60}$. En la tercera congregación provincial del Paraguay (1620), se estableció que cada jesuita debía dedicar al menos una hora diaria al estudio de una lengua indígena. A lo largo del siglo XVII, este tipo de prescripciones generaron debates. Los jesuitas extranjeros consideraban que implicaban una competencia desigual para ellos, pues los criollos tenían la ventaja de conocer algunos de los idiomas indígenas como lenguas maternas ${ }^{61}$. El reclamo no fue atendido por las autoridades y en 1726 Miguel Ángel Tamburini, prepósito general de la orden, volvía a recordar que "ninguno se ordene [sacerdote] sin saber la lengua índica; y si se hallare ordenado, se le detenga el grado de la Compañía hasta ser aprobado de lengua" ${ }^{62}$. Según Aliocha Maldavsky, un proceso similar tuvo lugar en la provincia del Perú. La obligatoriedad del aprendizaje de lenguas indígenas fue allí contestada por muchos jesuitas -tanto europeos como criollos- que no demostraban interés por las actividades misionales ${ }^{63}$. En Perú, la jerarquía de la orden tampoco dio lugar a los reclamos, y en Paraguay las actividades misionales tuvieron siempre una importancia mayor. El conocimiento de lenguas indígenas era entonces una característica imprescindible de los jesuitas de esta provincia.

Mapa 1. Distribución de libros en guaraní en el Paraguay y el Río de la Plata. Se excluyen las reducciones jesuíticas y franciscanas del Paraná y el Uruguay ${ }^{64}$.

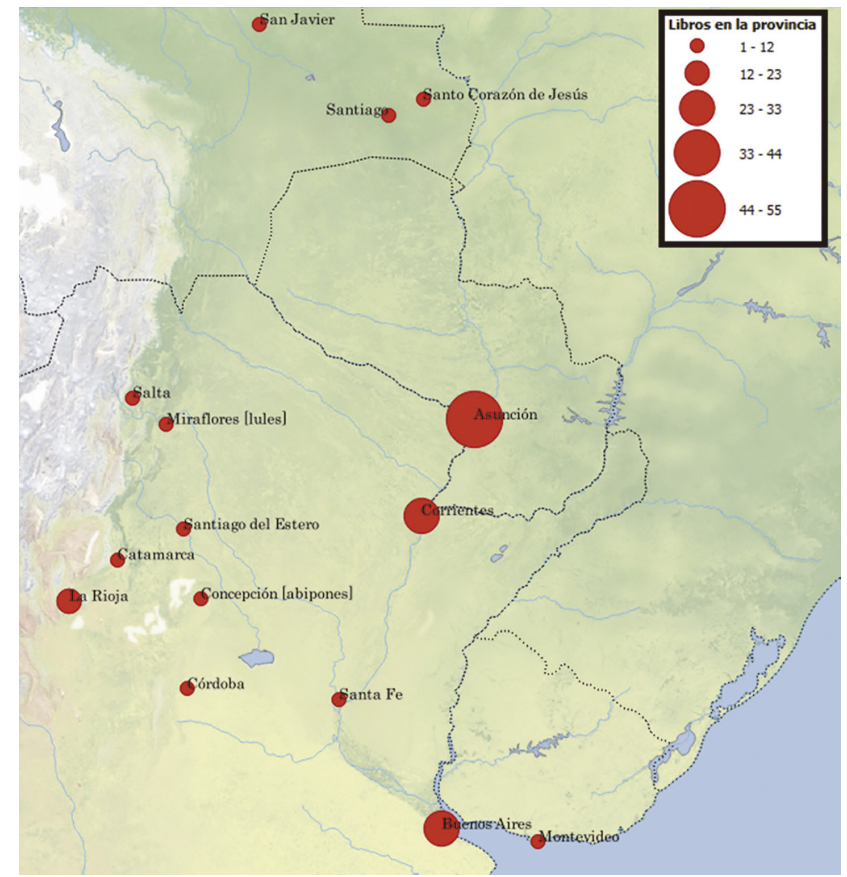

60 Daher, 2011: 64.

61 Fechner, 2015: 105-107.

62 Furlong, 1962: 473.

63 Maldavsky, 2012b: 259-305.

64 Elaboración propia (en QGIS) con base en las fuentes mencionadas en la nota 42. 
En el Paraguay y el Río de la Plata los evangelizadores trabajaron sobre varias lenguas, como el guaraní, el quechua, el lule, el chiquitano y otras. En los colegios jesuíticos existían libros en estas lenguas. En Asunción, por ejemplo, había libros en quechua, aymara y en las "dos lenguas generales de la provincia del Cuyo" 65 . En Buenos Aires era posible hallar libros de quechua y lule ${ }^{66}$. Sin embargo, los libros en guaraní estaban más extendidos y distribuidos que los de otras lenguas indígenas. Al parecer, los jesuitas estudiaban estas lenguas en los colegios ${ }^{67}$, aunque es difícil hallar evidencia que confirme la constitución de cátedras concretas en la provincia del Paraguay. Cuando se refieren al aprendizaje del guaraní, las cartas anuas del siglo XVIII aluden exclusivamente al estudio dentro de las reducciones del Paraná y el Uruguay, no en colegios ${ }^{68}$. Más allá de la existencia de cursos, la presencia de libros en ciertos colegios puede estar relacionada también con el traslado de jesuitas especialistas en la lengua hacia los mismos. Los dos mayores conocedores del guaraní en el siglo XVIII, José Insaurralde y Pablo Restivo, se desempeñaron como rectores de los colegios de La Rioja y Salta respectivamente. Al momento de la expulsión, el primero poseía 12 libros en guaraní y el segundo, 8. Resulta difícil no enlazar estos dos datos.

Donde sí parece haber existido una cátedra de guaraní es en Córdoba, ciudad de residencia del provincial y capital de la provincia jesuítica. Benito Moya indica que los jesuitas aprendían la lengua guaraní específicamente en el Colegio Máximo de la ciudad $^{69}$. La biblioteca jesuítica de Córdoba, la más grande de la región, conservaba ocho libros en guaraní. Además del valor educativo de las instituciones jesuíticas de la ciudad, Córdoba - específicamente la estancia de Santa Catalina, poseedora en sí misma de una importante biblioteca- era la sede del historiador oficial de la provin$\mathrm{cia}^{70}$. Probablemente muchos de los libros producidos o adquiridos por los jesuitas circulasen hacia esta ciudad, núcleo educativo y simbólico. No es casual que en la biblioteca del Colegio Máximo existiese uno de los cuatro únicos ejemplares de la lujosa e ilustrada edición en guaraní de De la diferencia entre lo temporal y lo eterno. Además, un inventario elaborado en la primera mitad del siglo XVIII de la biblioteca del Convento Grande de San Jorge, perteneciente a los franciscanos, da cuenta de la presencia de un Arte y bocabulario de la lengua guaraní de Ruiz de Montoya y de un Catesimo de la Doctrina Christiana escrito por Luis de Bolaños, indudablemente manuscrito. En este convento se formaban los misioneros franciscanos que trabajaban en pueblos de guaraníes ${ }^{71}$.

En dos ciudades en las que existían colegios jesuíticos se hablaba la lengua guaraní, Asunción y Corrientes. Tanto los indígenas como los hispano-criollos de estos territorios se comunicaban en este idioma. Los misioneros y sacerdotes usaban el guaraní en sus prácticas evangelizadoras, predicadoras y sacramentales. Entre los testimonios más significativos sobre la lengua hablada en Asunción y Corrientes

65 Gorzalczany - Olmos Gaona, 2006.

66 Revello, 1965: 71-72.

67 Baigorri Jalón - Araguás, 2007: 5-10.

68 Salinas - Folkenand, 2017.

69 Benito Moya, 2011: 296.

70 Lovay, 2017.

71 Esta información, todavía inédita, me ha sido proveída por Silvano G. A. Benito Moya, a quien estoy agradecido (comunicación personal; sobre este convento, véanse los trabajos del autor: Benito Moya, 2015, que menciona la gramática guaraní, y 2017). Actualmente, Benito Moya y su equipo se encuentran preparando una edición de los inventarios de los siglos XVIII y XIX de esta biblioteca. 
se encuentra el del misionero jesuita José Cardiel (1704-1781). Este declaraba en 1758 que "en la jurisdicción del Paraguay [Asunción], en que hay como 20.000 personas de sangre española, no se usa comunmente otra lengua que ésta guaraní, aunque mal, con muchos solecismos y barbarismos" 72 y añadía que "sucede casi lo mismo en la jurisdicción de la ciudad de las Corrientes, especialmente entre la gente del campo"73. Más adelante Cardiel daba precisiones sobre este guaraní criollo, que consideraba "un agregado de solecismos y barbarismos de la lengua guaraní y guaraní con castellano" "74, y finalizaba relatando su propia experiencia en Asunción y Corrientes:

Yo he estado tres años en el Paraguay, haciendo misión en la ciudad (que no hay más que una [Asunción]); en dos villas que tiene, llamadas Curuguatí y Villarica; y en las poblaciones campenses, y algún tiempo en las Corrientes; y me fué necesario aprender esta tan adulterada lengua para darme á entender ${ }^{75}$.

Otros testimonios confirman que incluso los estudiantes del colegio de Asunción hablaban en guaraní ${ }^{76}$. José Cayetano Paravicino ( $\left.\uparrow 1750\right)$, obispo de la ciudad a mediados del siglo XVIII, indicaba que en el colegio los niños se rehusaban a abandonar esta lengua ${ }^{77}$. Es comprensible entonces que esta ciudad albergase 55 libros en o sobre guaraní -la mayor proporción entre los colegios jesuíticos-, curiosamente muchos de ellos escritos o impresos en las vecinas misiones, con las cuales la élite criolla asuncena tuvo tantos conflictos económicos y políticos ${ }^{78}$. Cabe destacar que aquí como en otras regiones, el guaraní de los libros sería diferente del oral. La investigación lingüística está explorando la hipótesis de que existió una distinción de registros entre un guaraní coloquial y un guaraní cristiano, presente en la mayoría de los textos religiosos ${ }^{79}$. Posiblemente esto se haya visto acentuado en Asunción, aunque es muy poco lo que sabemos sobre el guaraní religioso hablado por los jesuitas de este territorio.

Santa Fe y Buenos Aires, otros dos espacios del litoral, poseían también una proporción no desdeñable de libros en guaraní. Esta era la lengua general colonial más cercana geográficamente a ambas ciudades. Casi todos los jesuitas llegados de Europa desembarcaban en Buenos Aires y es posible que allí transcurriese un período formativo lingüístico inicial para algunos, aunque no existió una cátedra de guaraní en el Colegio de San Ignacio. En Santa Fe y en Buenos Aires funcionaban sendas procuradurías de misiones ${ }^{80}$. Los procuradores se encargaban de recibir la producción de las reducciones (principalmente yerba mate) y colocarla en el mercado. Al mismo tiempo, eran los gestores de todos los intercambios de bienes y géneros entre las misiones y otros espacios. No parece que los libros hayan formado parte de estos intercambios - a diferencia de lo que sucedía en las procuradurías de Europa ${ }^{81}$, pero

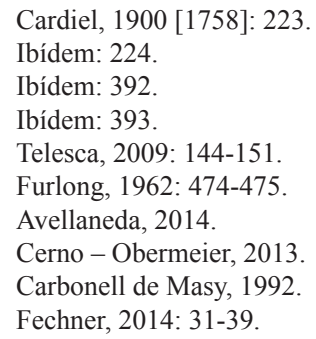


la existencia de estas instituciones da cuenta de una interconexión fuerte con el territorio guaraní. Los propios procuradores dependían del Superior de las misiones y solían tener larga experiencia en las mismas. Los indígenas -que a menudo sólo hablaban su lengua- podían viajar hasta estas ciudades. Se conservan remitos y recibos contables escritos en guaraní para el período posterior a la expulsión, por ejemplo varios relativos a bienes intercambiados entre el pueblo de Corpus y Buenos Aires a principios de la década de $1770^{82}$. En la procuraduría de Buenos Aires existía incluso una pequeña biblioteca. La fuerte relación entre Buenos Aires y las misiones tal vez explique por qué en esta ciudad se conservaba otro de los pocos ejemplares del lujoso libro ilustrado impreso en las reducciones, De la diferencia entre lo temporal $y$ lo eterno en guaraní ${ }^{83}$.

Algunos dialectos del guaraní también se hablaban hacia el oeste, a gran distancia de las reducciones del Paraná y el Uruguay. La población indígena chiriguana, asentada entre las ciudades de Salta y Tarija, hablaba el chiriguano o "guaraní del

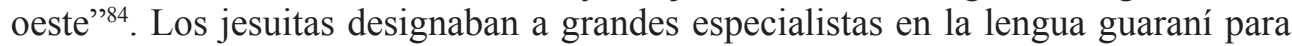
ocuparse de la evangelización de esta población, que nunca arrojó grandes frutos. Restivo y otros misioneros fueron trasladados desde las reducciones del Paraná y Uruguay para misionar entre los chiriguanos ${ }^{85}$. Aunque en el conjunto misional de Moxos (perteneciente a la provincia jesuítica del Perú; actualmente en Bolivia) no se hablaba guaraní ni chiriguano, en la biblioteca de la reducción de Santa Rosa (a la vera del río Guaporé o Iténez) existían cuatro vocabularios de lengua chiriguana ${ }^{86}$. No sabemos si corresponde a textos manuscritos elaborados en el Alto Perú o a los impresos guaraníes que circulaban desde el Paraguay, los cuales probablemente tuvieran utilidad para comunicarse con los chiriguanos. Por otro lado, el guaraní era la lengua hablada por una etnia que habitaba en las reducciones de chiquitos, los guarayos ${ }^{87}$. Tres reducciones chiquitanas, San Javier, Santo Corazón de Jesús y Santiago, poseían libros en guaraní. San Javier albergaba la biblioteca más grande de este conjunto misional y poseía un tomo de "Arte guaraní". Santiago poseía tres libros en guaraní: un tomo in octavo de "Doctrina de guaraní" (muy probablemente la Explicacion de el catechismo de Yapuguay), otro tomo in octavo de "Arte de lengua guaraní" y, por último, un "Catecismo de guaraní" in quarto (indudablemente el Catecismo de 1640).

Los libros en guaraní también eran útiles para comunicarse con la población indígena que hablaba esta lengua pero se encontraba circunstancialmente fuera del Paraná y el Uruguay. Ya nos hemos referido a los viajes que estos indios realizaban hacia Buenos Aires o Santa Fe. Contamos con un testimonio claro de este tipo de uso. En

82 A modo de ejemplo, véanse los papeles que comienzan: "Corregidor, Cavildo, haè Caziquez Corpuz tabapegua, oromombeù hupigua rete, opacatu Carai poroquatia oficiales [...]”. AGN, Sala IX, 18-06-06.

83 Para concluir con el espacio del Litoral, también debe destacarse que existían tres libros en guaraní en la residencia jesuítica de Montevideo.

84 Melià, 2003 [1969]: 103.

85 Las cartas anuas enfatizan que Restivo, "muy perito en la lengua guaraní,, fue designado para trabajar entre los chiriguanos en 1715 (Salinas - Folkenand, 2017: 74). Asimismo, las cartas anuas mencionan que, en 1732, para elegir qué misioneros se encargarían de la misión con estos indios, se "hizo una esmerada selección entre los pretendientes para esta misión, escogiéndose los cuatro siguientes: Rafael Jiménez, paraguayo; Julián Lizardi, vizcaíno; Ignacio Chomé, belga y José Pons, catalán, todos grandes lenguaraces del idioma guaraní, el propio de los chiriguanos" (Salinas - Folkenand, 2017: 270).

86 Romero Romero, 1992: 921.

87 Tomichá Charupá, 2017: 492-496. 
noviembre de 1748, el misionero Matías Strobl (1696-1769), que se ocupaba de la evangelización de los indios pampas en la reducción de Nuestra Señora del Pilar -en la frontera sur de Buenos Aires, actual Sierra de los Padres-solicitó a su compañero Jerónimo Rejón (1714-1776), que residía en la cercana reducción de Concepción de los Pampas -a la vera del río Salado-, que le fuera enviado un manual de lengua guaraní pues "alla esta debalde, y aquí me sirviria". Se refería, seguramente, al Manuale ad usum Patrum Societatis Iesu ${ }^{88}$. Es un manual de sacramentos basado en el ritual romano (aunque incorpora el ritual toledano), al que se añaden exhortaciones penitenciales que el confesor debía pronunciar ante el fiel. Los ritos sacramentales están en latín y en guaraní, pero las exhortaciones están íntegramente en guaraní. Según declaraba Strobl, ese texto le serviría "para administrar los Santos Sacramentos" Siete meses después repetía el mismo pedido ${ }^{90}$. En las reducciones jesuíticas de pampas vivían grupos de guaraníes, que los jesuitas habían llevado hasta la frontera sur para realizar tareas manuales y como ejemplo de "conversión" exitosa para la población indígena del lugar. Según un documento de 1746, existían 15 personas "entre españoles y tapes [guaraníes]" en la mencionada reducción de Concepción ${ }^{91}$. El propio Strobl, en la carta citada, alude a un "tape Ignacio" que oficiaba de cocinero en Nuestra Señora del Pilar. El uso de este libro en un espacio tan distante del Paraná y el Uruguay muestra la extensión de la lengua más allá de sus cauces habituales.

Los libros en guaraní estaban capilarmente distribuidos en el Río de la Plata y el Paraguay coloniales. Los misioneros, especialmente los jesuitas, estaban inmersos en un aprendizaje constante de lenguas indígenas. La distribución muestra que el guaraní debería dejar de pensarse únicamente como la lengua hablada por los indios de las reducciones jesuíticas y franciscanas de los ríos Uruguay y Paraná (y alrededores). Era también la lengua de Asunción y Corrientes y al menos el uso de los libros podía extenderse a otros lugares. Los misioneros ampliaban el alcance geográfico de una lengua cristiana inventada en principio en un territorio reducido. Esa generalización no respondía únicamente a la consideración de la misma como una lengua general (por jesuitas o franciscanos). Las prácticas territoriales y migratorias de la población guaraní parlante también están en la base de una dispersión previa de la lengua, anterior a la evangelización ${ }^{92}$.

Es posible considerar al guaraní como la lengua indígena por excelencia de este espacio. La distribución bibliografía amplió los marcos geográficos de la lengua. Al menos para el caso concreto de los jesuitas, más evidente, esto debería llevar a repensar la política lingüística provincial, ya no entendida como exclusiva de la región del Paraná y el Uruguay sino del conjunto del territorio. En este sentido, un dato es sintomático: aunque los indios en torno a Córdoba hablaban quechua, la cantidad de libros en guaraní en el Colegio Máximo duplicaba la de libros en la lengua general del Perú. Existió entonces una circulación capilar fundamentalmente regional de los

88 Palomera Serreinat, 2002. Sin embargo, este libro no aparece registrado en ninguno de los inventarios fuera de las misiones del Paraná y Uruguay.

89 Carta del Padre Matías Strobel al Padre Gerónimo Rejón. Nuestra Señora del Pilar, 20-XI-1748. AGN, Sala IX, 06-10-01.

90 Carta del Padre Matías Strobel al Padre Gerónimo Rejón. Nuestra Señora del Pilar, 26-V-1749. AGN, Sala IX, 06-10-01.

91 Estado del Pueblo de la Concepción de Indios Pampas del año 1746. Concepción, 1746. AGN, Sala VII, Colección Biblioteca Nacional, Legajo 189, f. 42. Agradezco a Nahuel Vasallo esta información.

92 Melià, 2003 [1969]: 101-141. 
libros. Aunque esta distribución se concentró en el Río de la Plata y el Paraguay, tuvo también una estela atlántica.

\section{Conexiones atlánticas}

Una exploración de los inventarios de otras realidades geográficas -como Europapermitiría rastrear soterrados intercambios y circulaciones atlánticas de los libros en guaraní. Esta no es una investigación que estemos en condiciones de realizar, puesto que requeriría un trabajo sistemático sobre una amplia masa documental, en gran parte inédita. Los inventarios de colegios jesuíticos, por ejemplo, son muy abundantes para la Península Ibérica producto del proceso de expulsión ${ }^{93}$. Unos pocos se encuentran editados en el marco de tesis doctorales recientes. Además, la Universidad de La Coruña ha digitalizado varios inventarios de bibliotecas particulares e institucionales de los siglos XVII y XVIII en el marco del proyecto de humanidades digitales Inventarios y Bibliotecas del Siglo de Oro (IBSO) y ha elaborado un motor de búsqueda para navegar el contenido de estos documentos ${ }^{94}$.

Los resultados de esta aproximación son parciales y arbitrarios, pero también significativos. La biblioteca del humanista y bibliófilo español Lorenzo Ramírez de Prado (1538-1658), que sumaba unos ocho mil volúmenes, fue inventariada en 1662. Allí podían encontrarse un Tesoro de la lengua guarani (1639), un Arte y bocabulario de la lengua guaraní (1640) y un Catecismo de la lengua guaraní (1640), todos ellos escritos por Ruiz de Montoya e impresos en Madrid ${ }^{95}$. En este inventario, los libros se registraron en categorías temáticas específicas. Los textos en guaraní figuran en la clase "Letras humanas", a su vez parte de la categoría más amplia "Artes liberales". En "Letras humanas" se encontraban además libros en o sobre otros idiomas de ultramar, como el japonés y el filipino. Los libros en guaraní no se ubicaron en una sección específica, correspondiente a América, sino que fueron concebidos probablemente a la manera de curiosidades de las Indias (en un sentido amplio). Como es evidente por las fechas, los libros alcanzaron muy pronto los estantes de esta biblioteca, pues su poseedor falleció tan sólo dieciocho años después de que fueran impresos.

En 1700, unas páginas preparatorias de la ya mencionada lujosa edición en guaraní de De la diferencia entre lo temporal y lo eterno fueron enviadas a Roma, según ha destacado Thomas Brignon. Las transportaron procuradores de la provincia del Paraguay y probablemente tenían el objetivo de obtener la aprobación de la máxima autoridad de la orden para la impresión del texto ${ }^{96}$. En estas páginas se mezclan textos impresos y manuscritos. Una contiene uno de los grabados que formaría parte de la edición, con la inscripción manuscrita "imago hic ex indoris ingenio fuit confecta", es decir "esta imagen fue producida en función del genio de los indios". Inscripciones similares reaparecen en otras de las páginas ${ }^{97}$.

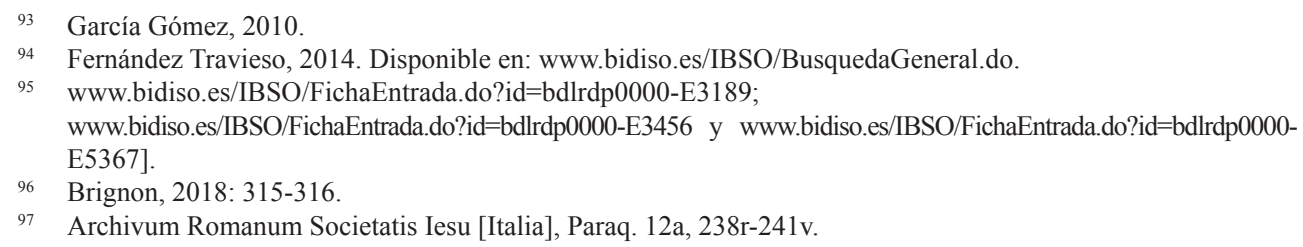


A su vez, el inventario del Colegio de La Encarnación de los jesuitas en Montilla (Córdoba, España), elaborado poco después de la expulsión, incluye los dos volúmenes de Ara Poru aguı̌yey haba de José de Insaurralde, impresos en Madrid en 1759$1760^{98}$. En un inventario de 1788 de la biblioteca del Monasterio de San Martín de Madrid, que poseía siete mil volúmenes, se alude a un Tesoro de la lengua guaraní de Ruiz de Montoya y por lo menos a uno de los volúmenes del Ara Poru aguı̌yey haba -registrado como "Isauralde (Josef) Ara Paris Aguiyllei Haba, o buen uso al tiempo. Madrid. 1759"99. El expulso y bibliófilo sevillano José de Silva y Dávila (1750-1829) también fue dueño de un ejemplar del primer volumen de Ara Poru, actualmente conservado en la Facultad de Teología de Granada junto a una parte de su biblioteca. El libro poseía el exlibris de Silva en una página de guarda, actualmente no visible ${ }^{100}$. El jesuita también escribió, en la última página de guarda, la palabra "Yucatan". Ara Poru está íntegramente en guaraní y posiblemente nadie en Europa pudiera leerlo. Silva, que quizás lo adquirió durante su exilio italiano o a su regreso a España a principios del siglo XIX, pudo haber confundió el guaraní con el idioma maya. ${ }^{101}$ Aunque merecería una investigación más profunda, la distinción entre dos idiomas indígenas americanos probablemente no fuese relevante para la naciente bibliofilia decimonónica.

Para terminar, cabe destacar que algunos jesuitas, enviados desde el Paraguay a Europa, cumplieron tareas más o menos relacionadas con las lenguas indígenas. Nos referimos a los procuradores, que además de transportar páginas en guaraní a Roma, se encargaron de la impresión de libros en lenguas americanas en España. Fue el caso de Antonio Ruiz de Montoya, procurador entre 1637 y 1643, y de Antonio Machoni, que desempeñó esta función entre 1731 y 1734. Ambos se ocuparon de imprimir sus propios libros, el primero en guaraní y el segundo en lule y tonocoté. Un caso similar es el de Juan de Escandón (1696-1772), procurador entre 1757 y 1764. Escandón tomó a su cargo la impresión de Ara Poru agǔ̌yey haba ${ }^{102}$. La actividad editorial de estos procuradores es todavía un tema vacante en la investigación. No deberíamos descartar que la distancia haya producido una cierta nostalgia o añoranza de la lengua, por tanto tiempo hablada en el Río de la Plata y el Paraguay. En diciembre de 1761, Escandón escribió una carta a su compañero Roque Ballester (1716-1787) desde el Puerto de Santa María (Cádiz), alusiva al envío de algunos bienes y las noticias de España. Escandón finalizó su breve misiva escribiendo, casi de manera espontánea, "Aypo ñote cheruba", es decir "eso solamente, mi Padre"103. Es probablemente uno de los primeros casos de escritura original en lengua guaraní desde la orilla europea del Atlántico y sintetiza el proceso de extensión y crecimiento de un idioma que indígenas y evangelizadores construyeron.

La presencia de estos libros en bibliotecas peninsulares y en los archivos jesuíticos de Roma da cuenta de que la circulación de la lengua - desde el punto de vista bibliográfico- tuvo un alcance atlántico. La circulación de libros y objetos suele pensarse como intercambios de Europa hacia América. Este caso informa de un inter-

\footnotetext{
Sánchez Herrador, 2016: 93-94 y 818.

www.bidiso.es/IBSO/FichaEntrada.do?id=modesa0000-E7154.

Carmen Escribano (bibliotecaria de la Facultad de Teología, comunicación personal).

Sobre Silva, véase: Herrera Puga, 1971.

Boidin - Cerno - Vega, 2020.

103 Carta del Padre Juan de Escandon al Padre Roque Ballester. Puerto de Santa María, 18-XII-1761. AGN, Sala IX, 06-10-05.
} 
cambio en el sentido inverso. También muestra una apropiación peculiar, diferente del uso práctico que tenían los libros en guaraní en América como parte de los saberes misionales ${ }^{104}$. Para los jesuitas peninsulares, estos libros seguramente fuesen una muestra de los trabajos apostólicos de los misioneros, incluso una inspiración para el "deseo de Indias" manifestado en las cartas indipetas ${ }^{105}$. Para los laicos como Ramírez de Prado o los bibliófilos como Silva, los textos en guaraní serían integrados en un coleccionismo de curiosidades, rarezas y bellezas. Esta distinción entre América y Europa prolonga una divergencia, establecida en los estudios sobre la Compañía de Jesús, entre el rol de los saberes prácticos en contextos misionales y el lugar de conocimientos más bien eruditos en instituciones como los colegios ${ }^{106}$. En el contexto de esta distinción, la circulación atlántica de libros en guaraní fue ciertamente limitada. Los que más presencia tuvieron en Europa fueron los libros que los jesuitas habían hecho imprimir en Madrid. Los productos eminentemente prácticos y pragmáticos de la imprenta de las reducciones (1700-1727), de una tirada muy limitada, no cruzaron el Atlántico, por lo menos en la primera mitad del siglo XVIII ${ }^{107}$.

\section{Conclusión}

A lo largo de este artículo, contabilizamos e identificamos los libros en guaraní presentes en las bibliotecas del Río de la Plata y el Paraguay en el siglo XVIII. Determinamos que existió una distribución capilar de estos libros, la cual puede ser explicada por la presencia de redes subterráneas para la circulación de estos materiales -en especial, la movilidad de los jesuitas a lo largo del territorio y la obligación que tenían los misioneros de aprender lenguas indígenas. Los libros en guaraní alcanzaron ciudades y pueblos en que no se hablaba esta lengua, de modo que las bibliotecas ampliaron los marcos geográficos de la misma. Estas afirmaciones constituyen un punto de partida para una historia cultural que enlace la circulación de libros con las políticas lingüísticas coloniales. Una historia de este tipo enfrenta retos y tareas pendientes: a) profundizar el conocimiento de los colegios y cátedras coloniales, en especial sus dimensiones bibliográficas y lingüísticas; b) rastrear los movimientos geográficos de los indios guaraníes que, a partir de las misiones del Paraná y el Uruguay, trasladaron su lengua hacia otros proyectos misionales, desde el Chaco hasta el sur de Buenos Aires; c) investigar las conexiones intelectuales, bibliográficas y culturales entre distintos conjuntos misionales, en especial Paraná-Uruguay y las misiones de Moxos y Chiquitos; d) explorar la actividad editorial de los procuradores de órdenes religiosas, que se valieron de imprentas europeas para producir libros en lenguas indígenas, "desarraigados" del espacio europeo; e) estudiar en detalle los inventarios de bibliotecas europeas, lo que serviría para identificar soterradas circulaciones de libros desde América hacia Europa. Estos aspectos permitirían discutir cuál fue el rol de las bibliotecas temprano-modernas para la constitución de redes geográficas, culturales y lingüísticas de más amplio alcance.

\footnotetext{
104 Castelnau-L'Estoile - Copete - Maldavsky - Zupanov, 2011; Wilde, 2011.

105 Maldavsky, 2012a y 2012b: 233-248.

106 Maldavsky, 2012b.

107 Con posterioridad a 1770-1780, muchos jesuitas o ex jesuitas producirían textos sobre guaraní en el exilio y surgiría una lingüística comparada profundamente interesada por las lenguas americanas.
} 


\section{Referencias bibliográficas}

Adoue, Cecilia - Orantin, Mickaël - Boidin, Capucine. "Diálogos en guaraní, un manuscrit inédit des réductions jésuites du Paraguay (XVIIIe siècle)". Nuevo Mundo Mundos Nuevos, Débats, puesto en línea el 1 de diciembre de 2015.

Alcalá Donegani, Luisa Elena. “'De compras por Europa': procuradores jesuitas y cultura material en Nueva España”. Goya. Revista de arte, n 318 (2007), 141-158.

Avellaneda, Mercedes. Guaranies, criollos y jesuitas. Luchas de poder en las revoluciones comuneras del Paraguay, siglos XVII y XVIII. Asunción: Editorial Tiempo de Historia, 2014.

Baigorri Jalón, Jesús - Alonso Araguás, Icíar. "Lenguas indígenas y mediación lingüística en las reducciones jesuíticas del Paraguay (S. XVII)". Mediazioni online. Revista online di studi interdisciplinari su lingue e culture, 2007.

Benito Moya, Silvano G. A. La Universidad de Córdoba en tiempos de reformas (17011810). Córdoba: Centro de Estudios Históricos "Prof. Carlos S. A. Segreti", 2011.

- "Bibliotecas y libros en la cultura universitaria de Córdoba durante los siglos XVII y XVIII”. Información, cultura y sociedad, nº 26 (2012), 13-39.

— "Pensamiento tradicional e Ilustración. La biblioteca del convento franciscano de Córdoba (siglos XVIII y principios del XIX)". En La historia intelectual y el movimiento de las ideas en América Latina, siglos XIX-XX, editado por De la Mora V., Rogelio - Cancino, Hugo. Xalapa: Universidad Veracruzana, 2015, 375-399.

— "Libros y saberes. Una biblioteca conventual que hizo las veces de universitaria en Córdoba del Tucumán". En Aspectos de la modernidad latinoamerica: rupturas y discontinuidades, editado por De la Mora Valencia, Rogelio - Cancino Troncoso, Hugo. Xalapa: Universidad Veracruzana, 2017, 257-278.

Bertrand, Gilles - Cayuela, Anne - Del Vento, Christian - Mouren, Raphaële (eds.). Bibliothèques et lecteurs dans l'Europe moderne (XVIIe-XVIIIe siècles). Genève: Droz, 2016.

Boidin, Capucine. "Pensar la modernidad/colonialidad en guaraní (XVI-XVIII)". Cuadernos de antropología social, vol. 44 (2016), 7-25.

— "Mots guarani du pouvoir, pouvoir des mots guarani. Essai d'anthropologie historique et linguistique (XIX-XVI et XVI-XIX)”. Tesis de habilitación, Université Sorbonne Nouve1le, 2017.

Boidin, Capucine - Cerno, Leonardo - Vega, Fabián R. “This Book Is Your Book'. Jesuit Editorial Policy and Individual Indigenous Reading in Eighteen-Century Paraguay". Ethnohistory, vol. 67, n 2 (2020), 247-267.

Bouza, Fernando. Corre manuscrito. Una historia cultural del Siglo de Oro. Madrid: Marcial Pons Historia, 2001.

Brabo, Francisco Javier (ed.). Colección de documentos relativos a la expulsión de los Jesuitas de la República Argentina y del Paraguay en el Reinado de Carlos III. Madrid: Estudio Tipográfico José María Pérez, 1872a.

- (ed). Inventarios de los pueblos de misiones. Madrid: Imprenta y Estereotipia de M. Rivadeneyra, $1872 \mathrm{~b}$.

Brignon, Thomas. "Du copiste invisible à l'auteur de premier ordre. Le traduction collaborative de textes religieux en guarani dans les réductions jésuites du Paraguay". Sociocriticism, vol. 33 (junio 2018), 299-338.

— "Del exemplum al tekokue. Traducción colaborativa, reescritura y cultivo del arte retórico en tres relatos ejemplares en guaraní de Nicolás Yapuguay y Pablo Restivo (17241727)". Estudios paraguayos, vol. 36, nº 2 (2019), 41-73. 
Carbonell de Masy, Rafael. Estrategias de desarrollo rural en los pueblos guaranies (16091767). Barcelona: Antoni Bosch Editor, 1992.

Cardiel, José. Misiones del Paraguay. Declaración de la verdad. Obra inédita del P. José Cardiel, religioso de la Compañia de Jesús. Editado por Pablo Hernández. Buenos Aires: Imprenta de Juan A. Alsina, 1900 [1758].

Castelnau L'Estoile, Charlotte de. "'En raison des conquêtes, de la religion et du commerce'. L'invention de la langue générale dans le Brésil du XVIe siècle". Mélanges de la Casa de Velázquez. Nouvelle série, $\mathrm{n}^{\circ}$ 45-1 (2015), 77-98.

Castelnau-L'Estoile, Charlotte de - Copete, Marie-Lucie - Maldavsky, Aliocha - Zupanov, Ines G. (eds.). Missions d'évangélisation et circulation des savoirs: XVIe-XVIIIe siècle. Madrid: Casa de Velázquez, 2011.

Cerno, Leonardo - Obermeier, Franz. "Nuevos aportes de la lingüística para la investigación de documentos en guaraní de la época colonial (Siglo XVIII)". Folia Histórica del Nordeste, vol. 21 (2013), 33-56.

Chartier, Roger. Libros, lecturas y lectores en la Edad Moderna. Madrid: Alianza, 1994.

Comadrán Ruiz, Jorge. Bibliotecas cuyanas del siglo XVIII. Mendoza: Universidad Nacional de Cuyo, 1961.

Daher, Andrea. "De los intérpretes a los especialistas: el uso de las lenguas generales de América en los siglos XVI y XVII". En Saberes de la conversión. Jesuitas, indígenas e imperios coloniales en las fronteras de la cristiandad, editado por Wilde Guillermo. Buenos Aires: SB, 2011, 61-80.

Draghi Lucero, Juan. "La biblioteca de los jesuitas de Mendoza durante la época colonial”. Revista de Historia, vol. 1, no 1 (1949), 95-165.

Estenssoro, Juan Carlos. "Las vías indígenas de la occidentalización. Lenguas generales y lenguas maternas en el ámbito colonial americano (1492-1650)". Mélanges de la Casa de Velázquez. Nouvelle série, $\mathrm{n}^{\circ}$ 45-1 (mayo 2015), 15-36.

Estenssoro, Juan Carlos - Itier, César. "Présentation (dossier Langues indiennes et empire dans l'Amérique du Sud coloniale)". Mélanges de la Casa de Velázquez. Nouvelle série, $n^{\circ}$ 45-1 (mayo 2015), 9-14.

Fechner, Fabian. "Las tierras incógnitas de la administración jesuita: toma de decisiones, gremios consultivos y evolución de normas". Histórica, vol. 38, n 2 (2014), 11-42.

— "Un discurso complementario sobre la posición jurídica de la población indígena colonial: las congregaciones provinciales en la provincia jesuítica del Paraguay (1608-1762)". En Las agencias de lo indígena en la larga era de globalización. Microperspectivas de su producción y representación desde la época colonial temprana hasta el presente, editado por Köhler, Romy - Ebert, Anne. Berlin: Gebr. Mann Verlag, 2015, 99-118.

Fernández Travieso, Carlota. "Base de datos sobre Inventarios y Bibliotecas del Siglo de Oro (IBSO). Utilidad y posibilidades”. Janus. Estudios sobre el Siglo de Oro, no Anexo 1. "Humanidades Digitales: desafíos, logros y perspectivas de futuro" (2014), 175-183.

Fraschini, Alfredo Eduardo (ed.). Index librorum Bibliothecae Collegii Maximi Cordubensis Societatis Jesu anno 1757: edición crítica, filológica y biobibliográfica. Vol. 1. Córdoba: Universidad Nacional de Córdoba, 2005a.

- (ed). Index librorum Bibliothecae Collegii Maximi Cordubensis Societatis Jesu anno 1757: edición crítica, filológica y biobibliográfica. Vol. 2. Córdoba: Universidad Nacional de Córdoba, 2005b.

Furlong, Guillermo. Bibliotecas argentinas durante la dominación hispánica. Buenos Aires: Huarpes, 1944. 
- Orígenes del arte tipográfico en América, especialmente en la República Argentina. Buenos Aires: Editorial Huarpes, 1947.

- Historia y bibliografía de las primeras imprentas rioplatenses. 1700-1850. Vol. I. Buenos Aires: Guarania, 1953.

- Misiones y sus pueblos de guaranies. Buenos Aires: Imprenta Balmes, 1962.

Galán García, Agustín. El "Oficio de Indias” de Sevilla y la organización económica y misional de la Compañía de Jesús (1566-1767). Sevilla: Fundación Fondo de Cultura de Sevilla, 1995.

García Gómez, María Dolores. Testigos de la memoria. Los inventarios de las bibliotecas de la Compañía de Jesús en la expulsión de 1767. Alicante: Universidad de Alicante, 2010.

Gorzalczany, Marisa Andrea - Olmos Gaona, Alejandro. La biblioteca jesuitica de Asunción. Buenos Aires: Edición de los autores, 2006.

Gutiérrez, Ramón. "Las bibliotecas de las misiones jesuíticas. Consideraciones sobre la de Candelaria”. Investigaciones y Ensayos, n 54 (2004), 43-55.

Herrera Puga, Pedro. Una personalidad inédita de la Ilustración. Granada: Universidad de Granada, 1971.

Llamosas, Esteban F. La literatura jurídica de Córdoba del Tucumán en el siglo XVIII: bibliotecas corporativas y privadas: libros ausentes, libros prohibidos. Lerner Editora, 2008.

— "Probabilismo, probabiliorismo y rigorismo. La teología moral en la enseñanza universitaria y en la praxis judicial de la Córdoba tardocolonial". CIAN. Revista de historia de las universidades, vol. 14, $\mathrm{n}^{\circ} 2$ (2011), 281-294.

— "La Biblioteca Cordobesa de la Orden Franciscana: notas sobre moral y derecho como aval de la monarquía". Cuadernos de Historia, no 22 (2012), 109-123.

Lovay, Silvana M. "Las bibliotecas en las estancias jesuíticas. El caso de Santa Catalina (Córdoba-Argentina)". Antiguos jesuitas en Iberoamérica, vol. 5, nº 2 (2017), 166-200.

Maldavsky, Aliocha. "Pedir las Indias. Las cartas indipetae de los jesuitas europeos, siglos XVI-XVIII, ensayo historiográfico". Relaciones. Estudios de historia y sociedad, vol. 33, $\mathrm{n}^{\mathrm{o}} 132$ (2012a), 147-181.

- Vocaciones inciertas. Misión y misioneros en la provincia jesuita del Perú en los siglos XVI y XVII. Lima: Consejo Superior de Investigaciones Científicas, $2012 \mathrm{~b}$.

Medina, José Toribio. Historia de la imprenta en los antiguos dominios españoles de América y Oceanía. Vol. 2. Santiago de Chile: Fondo Histórico y Bibliográfico José Toribio Medina, 1958.

Melià, Bartomeu. "Fuentes documentales para el estudio de la lengua guaraní de los siglos XVII y XVIII”. Suplemento Antropológico, vol. 5 (1970), 113-161.

_ "Breve introducción para aprender la lengua guaraní [Alonso Aragona, 1627]". Amerindia, vol. 4 (1979), 23-62.

- La lengua guarani del Paraguay. Historia, sociedad y literatura. Madrid: Editorial MAPFRE, 1992.

- La Lengua Guarani en el Paraguay colonial. Asunción: CEPAG, 2003 [1969].

Neumann, Eduardo. Letra de Índios. Cultura escrita, comunicação e memória indígena nas Reduções do Paraguai. São Bernardo do Campo: Nhanduti Editora, 2015.

Obermeier, Franz. "Die Inventare der Jesuitenreduktionen bei der Vertreibung des Ordens aus dem La-Plata-Raum im 18. Jahrhundert und ihre buch- und bibliotheksgeschichtliche Bedeutung”. Wolfenbütteler Notizen zur Buchgeschichte, vol. 41, nº 1-2 (2016), 77-105.

— "El Apéndice de la Colección de obras impresas y manuscritas [1853] de Pedro de Angelis. Una reconstrucción de la parte etnolingüística." Antiguos jesuitas en Iberoamérica, vol. 5, $n^{\circ} 2$ (2017), 3-27. 
Palomera Serreinat, Lluís. Un ritual bilingüe en las reducciones del Paraguay: el Manual de Loreto (1721). Editorial Verbo Divino-Universidad Católica Boliviana, 2002.

Parada, Alejandro E. "Tipología de las bibliotecas argentinas desde el período hispánico hasta 1830: Una primera clasificación provisional". Información, cultura y sociedad, $\mathrm{n}^{\circ} 9$ (diciembre 2003), 75-94.

Revello, José Torre. "Bibliotecas en el Buenos Aires antiguo desde 1729 hasta la inauguración de la Biblioteca Publica en 1812". Revista de Historia de América, no 59 (1965), $1-148$.

Robledo de Selassie, Beatriz. Compañia de Jesús. Inventario y tasación de sus bienes en San Miguel de Tucumán al 29 de mayo de 1768. Por la Junta Real de Temporalidades. San Miguel de Tucumán: Instituto de Investigaciones de Historia Económica y Social, UNT, 1976.

Romero Romero, Catalina. "Tres bibliotecas jesuitas en pueblos de misión: Buenavista, Paila y Santa Rosa, en la región de Moxos”. Revista de Indias, vol. 52, nº 195 (1992), 889-922.

Salinas, María Laura - Folkenand, Julio (eds.). Cartas anuas de la Provincia Jesuítica del Paraguay. 1714-1720. 1720-1730. 1730-1735. 1735-1743. 1750-1756. 1756-1762. Asunción: Centro de Estudios Antropológicos de la Universidad Católica, 2017.

Sánchez Herrador, Miguel Ángel. "La Biblioteca del Colegio de La Encarnación de los jesuitas de Montilla". Tesis doctoral, Universidad de Córdoba, 2016.

Telesca, Ignacio. "Como dolor de Tripas'. El colegio de Asunción del Paraguay entre las revueltas comuneras y la expulsión”. En Tras los Expulsos. Cambios demográficos y territoriales en el Paraguay después de la expulsión de los jesuitas. Asunción: Centro de Estudios Antropológicos de la Universidad Católica, 2009, 111-160.

Thun, Harald - Cerno, Leonardo - Obermeier, Franz (eds.). Guarinihape tecocue - Lo que pasó en la guerra (1704-1705). Memoria anónima en guaraní del segundo desalojo de la Colonia del Santo Sacramento. Kiel: Westensee -Verlag, 2015.

Tomichá Charupá, Roberto. "La política de reducciones y sus efectos en la sociedad chiquitana (siglos XVII-XVIII)". En Reducciones. La concentración forzada de las poblaciones indígenas en el Virreinato del Perú, editado por Saito, Akira - Rosas Lauro, Claudia. Lima: Fondo Editorial de la Pontificia Universidad Católica del Perú y National Museum of Ethnology, 2017, 477-507.

Vega, Fabián R. "Los saberes misionales en los márgenes de la monarquía hispánica: los libros de la reducción jesuítico-guaraní de Candelaria". Archivum Historicum Societatis Iesu, vol. LXXXVI, nº 172 (2017), 7-56.

— "La dimensión bibliográfica de la reducción lingüística. La producción textual jesuítica en guaraní a través de los inventarios de bibliotecas". Nuevo Mundo Mundos Nuevos, Débats, puesto en línea el 10 de diciembre de 2018.

Wilde, Guillermo. "Adaptaciones y apropiaciones en una cultura textual de frontera: impresos misionales del Paraguay Jesuítico”. História Unisinos, vol. 18, no 2 (2014), 270-286.

- ed. Saberes de la conversión. Jesuitas, indígenas e imperios coloniales en las fronteras de la cristiandad. Buenos Aires: SB, 2011.

Wilde, Guillermo - Vega, Fabián R. "De la indiferencia entre lo temporal y lo eterno. Élites indígenas, cultura textual y memoria en las fronteras de América del Sur". Varia Historia, vol. $35, \mathrm{n}^{\circ} 68$ (2019), 273-318. 